\title{
Partnership of Research Institutions and Manufacturing Companies: Russian Experience
}

\author{
Vladimir llyich Savinkov ${ }^{1}$ \\ Grigory Arturovitch Kliucharev² \\ ${ }^{1}$ Federation Council, Moscow, Russian Federation \\ Email: visavinkov@council.gov.ru \\ 2Institute of Sociology of the Russian Academy of Sciences, Moscow, Russian Federation \\ Email: kliucharevga@mail.ru
}

Doi:10.5901/mjss.2015.v6n4s4p403

\begin{abstract}
State policy should at all times offer full support to the innovative development of all sectors of the economy. To accomplish this objective, the state needs to augment the scientific potential of universities and assist in transforming this potential into actual production. It is a two-in-one task: on the one hand, to make sure that universities are adequately preparing specialists capable of performing creative tasks in both production and management; and, on the other hand, to see that universities are attractive for innovative production companies involved in the core sectors of the economy and whose cooperation in scientific areas can strengthen their position in the international market. This article provides a structural analysis of the main principles of state policy in the area of science and an evaluation of its potential to enhance cooperation between universities and production companies.
\end{abstract}

Keywords: innovative production, academic cooperation, specialist with an analytical mindset, state policy.

\section{Introduction}

In 1990-2000, Russia went through extensive and profound social and economic transformation, the outcomes of which were primarily social and political. The evidence of the latter is the implementation of exchange relations in the country's economy. However, the economy proved to be quite inert and is still struggling towards its rightful place in the international market of goods and services. The technological modernization of the economy, as well as innovative types of production, is absolutely urgent for Russia. For the last five years the Russian Government has provided a good foundation for stronger ties between science and production having financed different types of measures aimed at this purpose. Resolutions of the Russian Government \#218 and \#219 issued on April 9, 2010, and Order \#276 of July 29, 2009 "On The List Of Indicators, Criteria And Frequency of Evaluating the Effectiveness of Development Programs for Universities categorized as a "National Research University" determine the main aim of the nationwide measures, i.e. to promote the scientific potential of universities and strengthen their links with industrial companies and research organizations. The problem of interaction between innovative production companies, universities and research organizations has been studied by members of the Russian Academy of Sciences Osipov G.V., Strikhanov M.N., professors Sheregi F.E., Klyuchareva G.A. The authors focused on the mechanisms of such like interaction and compare these mechanisms with those accumulated by international partners and described in literature.

\section{Measures Taken by Universities for Effective Interaction with Production Companies}

As modern technology has both modernized the economy and focused on innovation production, it is now incumbent for universities to concentrate on the analytical component of the educational process and pay more attention to training engineers-innovators (Osipov et al., 2014, p.4-28). In the past five years, the state has offered financial support as a means of strengthening the ties between science and education. The main purpose of government measures has always been to help enhance the scientific potential of universities and to strengthen their ties with production companies and 
research organizations ${ }^{1}$. Another measure that has helped is the fact that at least $20 \%$ of the state budget funds and investments of commercial enterprises provided to universities are to be used on nothing but research and development. This approach is based on the successful experience of economically developed countries and is shown in Fig. 1.

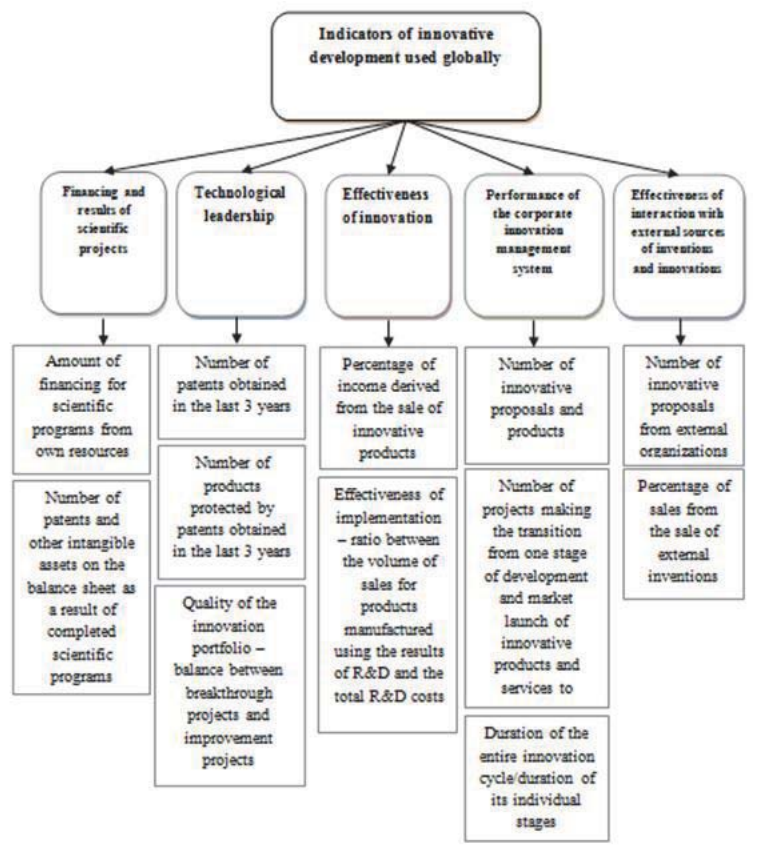

Figure 1. Indicators of innovative development programs used globally

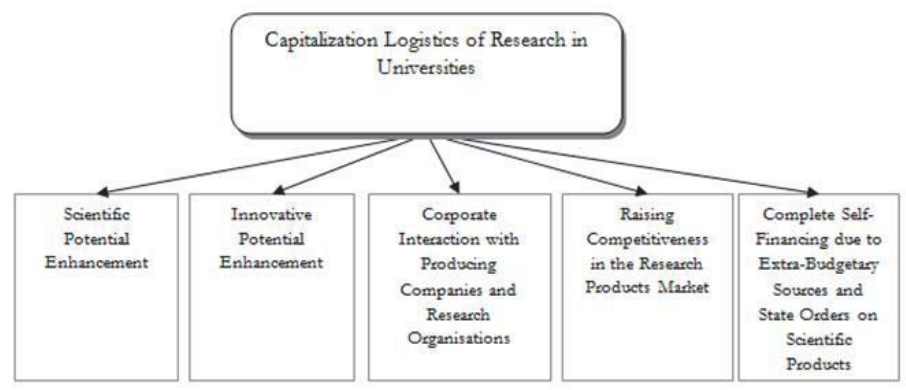

Figure 2. Capitalization Logistics of Research in Universities

To stimulate demand, in the Russian market, for the results of R\&D conducted by universities, there must be a guarantee of effective cooperation between universities and the best production companies in the following categories:

- Identification of subject areas (scientific, technological) and scope of joint research (design, development and technological work);

- Development of research programs in cooperation with production companies and research organizations. These programs are aimed at establishing mechanisms for the exchange of scientific, technological and

1 Decrees of the Russian Government №218 and №219 dated 9 April 2010; Order of the Ministry of Education and Science of the Russian Federation №276 "On the list of indicators, criteria and frequency of evaluation of the effectiveness of development programs of universities classified as "National Research Universities" dated 29 July 2009. 
marketing information; development of a common vision of new scientific and technological development; the creation of a system of management for research (development, design and technological work) in universities, taking into account the needs of specific production companies and sectors of the economy;

- Implementation of programs to improve the education of engineers and managers for future careers in hightech sectors and industries. In these cases, production companies would take an active part in both the enhancement of educational programs and teaching. Moreover, they would assist in the development of internships and in-house training programs for undergraduates and postgraduates as well as faculty members of universities in production companies. Finally, they would add to the development of a system of continuous education for personnel working in production companies.

Universities play a major role in the interaction between production companies and research organizations. Accordingly, a successful collaboration is not possible unless universities substantially improve their technical and technological bases of university scientific research, and indeed this issue has been taken into account by the Russian Federation. Thus, with the state's assistance, these crucial aspects of university science are being subjected to an innovative environment and buoyed by the financial stimulation of the interaction and cooperation between universities and industry. Both small innovative university enterprises and major research organizations are involved in such forwardlooking and creative cooperation between universities and production companies.

The current logistics of scientific cooperation between production companies and universities in Russia is schematically shown in Fig. 2

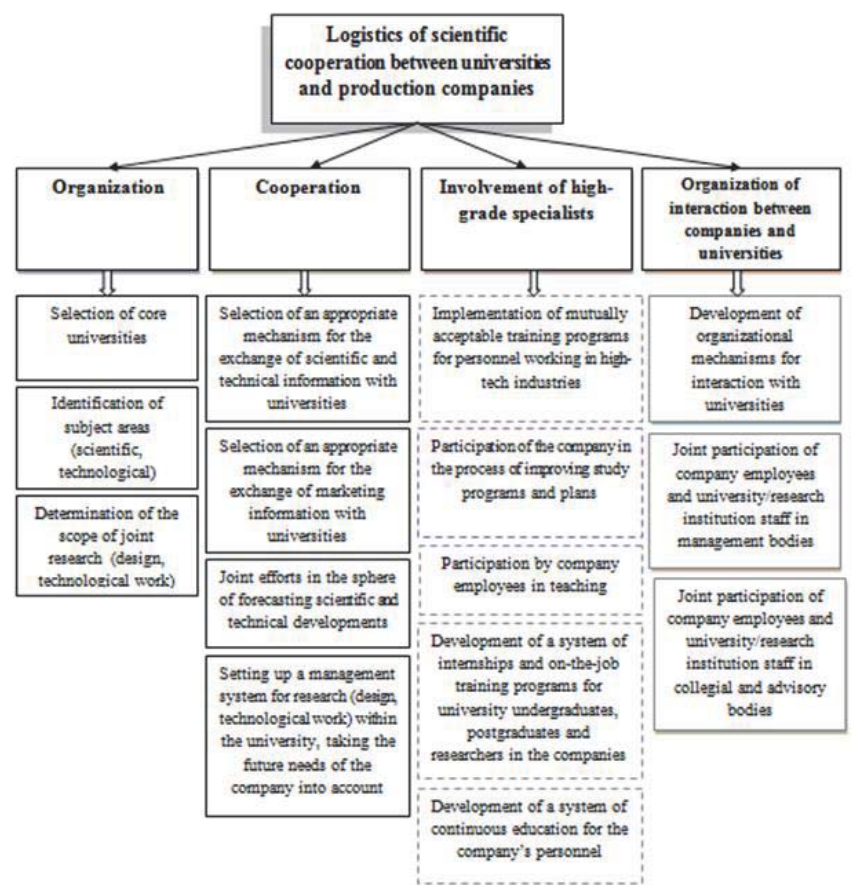

Figure 3. Logistics of the scientific cooperation between universities and production companies

In accordance with the Russian Federal Law "On Higher and Post-University Professional Education", the efforts of the universities participating in scientific cooperation with production companies and research organizations are focused on completing the following tasks:

- Development of innovative facilities/infrastructure (business incubators, techno parks, techno park zones, centres for innovation and technology, engineering centres, certification centres, centres for technology transfer, centres for collective use, centres of scientific and technical information, centres for innovative consulting, and other components of innovative infrastructure); 
- Furnishing innovative facilities with modern equipment and providing technical maintenance of said equipment;

- Furnishing innovative facilities with software required for the implementation of the results of the scientific and technical intellectual activity; with exclusive rights to this software belonging to educational institution;

- Providing legal defense of intellectual products;

- Implementation and development of special-purpose and advanced training programs for personnel involved in the sphere of small-scale innovative entrepreneurship, including initiatives for students, postgraduates and young scientists;

- Development of guidelines and methodologies for small and medium-sized enterprises;

- Organisation of internships and advanced study programs for educational institutions' employees to teach them innovative entrepreneurship and technologies developed by foreign universities with efficient innovative infrastructures;

- Involvement/invitation of foreign and Russian expert consultants in the area of technology transfer;

- Establishing joint venture companies in which university faculty members are to provide methodological assistance.

As scientific cooperation programs unfold, universities and production companies should pay special attention to corporate mechanisms and structures that support the development and implementation of scientific products emanating from universities. They should also supervise the establishment of management systems for scientific cooperation, directing their attention to the following key areas:

- Implementation of transparent corporate technological policy for the market, company owners and the state, while following regular standards of commercial secrecy and defending intellectual property including specialists "know-how", production secrets, etc. This policy should include the provision of information to stakeholders regarding future scientific and technological requirements of companies;

- Approval of target and key performance indicators for innovative development directed at all levels of management, including senior positions;

- Substantial expansion of R\&D implementation conducted in the higher education sector; utilization of best technologies, products and services developed by small and medium-sized innovative enterprises (Sheregi et al., 2014, №1-3).

The measures listed above constitute the development of a large-scale technological platform, i.e. material grounds for effective scientific cooperation of universities, innovative companies and research organizations. The process of interaction involves a broad mechanism implemented through a complex network of "channels." The ultimate success of these measures will require vigilant monitoring by competent management. These cooperation/interaction channels are defined by indicators specified in government resolutions. Their role is twofold: (1) They serve as the main performance evaluation criteria for the development of technical and technological bases of university science; and (2) they allow for an accurate evaluation of the effectiveness of the universities' participation in scientific cooperation with companies and research organizations. In addition to "statistical" measures aimed at establishing the basis for innovative cooperation among universities, production companies and research organizations in the areas previously discussed, it is also necessary to introduce a series of directives aimed at evaluating the economic effectiveness of it all, which can be obtained by using indicators of, for example, successful transfer of a research product into innovative production, and then by measuring the ratio between the cost of research and income from said innovative products.

The main goal of the state policy in the higher education sector is to strengthen university scientific potential and make it a functional instrument by stimulating cooperation with innovative production companies and research organizations. However, the "logistics" describes only the first stage of a lengthy implementation process required in the framework of partnerships/cooperation. Successful scientific cooperation between universities, production companies and research organizations implies the following: development of a detailed joint business plan which would contain calculations for personnel, finance and technology required to conduct both the scientific research and the transfer of scientific products into the innovative production sphere; an evaluation of the market situation and a determination of the time lag with respect to the sustainability of innovative products in the internal and international markets of products and services. Accordingly, the risks for each independent stage of scientific and innovative cooperation between partners must be identified and modeled. Finally, we must make a calculation of the desired rate of return for scientific cooperation which, once reached, would signify that the scientific/research activity of universities had become self-sufficient.

\section{Experience of Universities Partnership with Production Companies: Research Results}

The expectations of the Russian Government on scientific cooperation between producing companies, universities and 
research organizations are as follows:

- Mobilizing public and private resources to enhance innovative production based on better cooperation of production with science and education;

- Better systematic conditions for innovations within the country and regions;

- Increased capacity of highly qualified researchers and professionals;

- Growth of economic indicators: higher labour productivity in innovative production, competitiveness of new products in domestic and international markets of goods and services.

- The economic and social effects of innovation cooperation between universities, research organizations and industrial companies, affecting the management are expected to be improving through:

- Coordination of research and development to address their fragmentation and duplication;

- Focusing on strategic scientific trends thus contributing to competitive innovative production;

- Mobilization and consolidation of intellectual, material, technical and financial resources of the state and business entities of the Russian Federation aimed at improving the utilization of expensive scientific and industrial equipment;

- Creating attractive conditions for visiting researchers through intensifying and improving the quality of scientific work;

- Creating an attractive career environment for young professionals;

- Implementing a wider range of competitive innovative products in the domestic market for goods and services;

- Creating conditions for equal international partnership between university academia, research organizations and industrial companies.

In 2011-2015, the Centre for Social Forecasting and Marketing conducted research into the efficiency of interaction between universities and industrial companies aimed at joint implementation of research programs and stimulating innovative production (F.E. Sheregi, Project leader). The conception and tools used to process the primary expert information are presented in Figures 4-82.

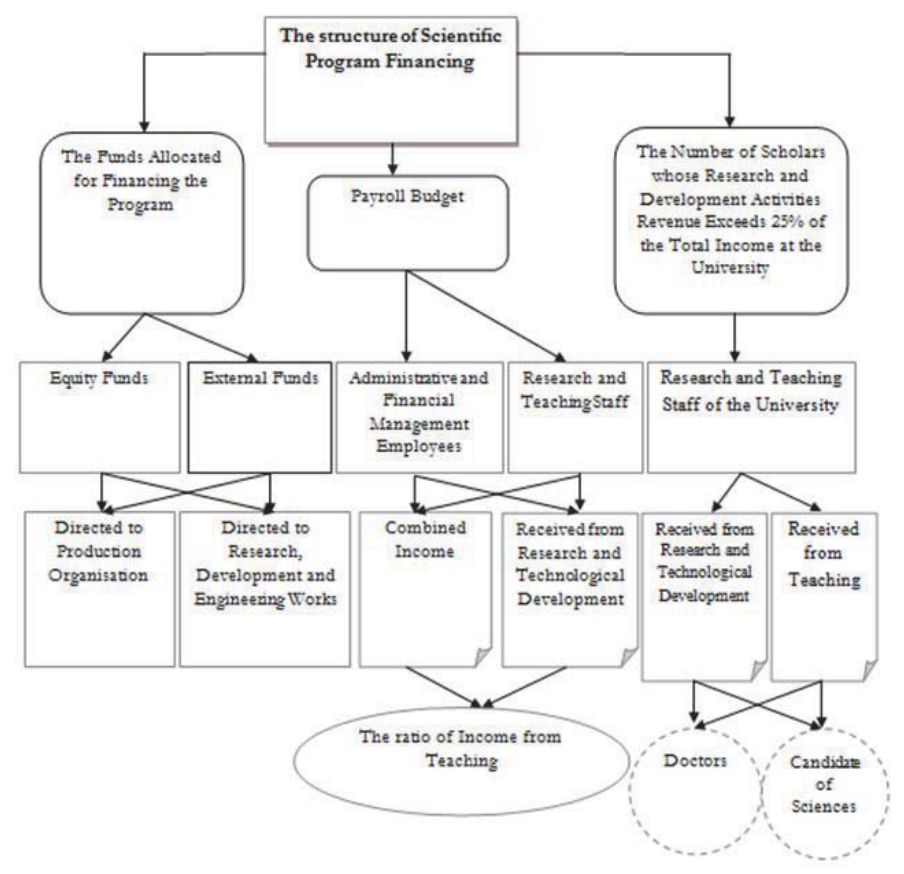

Figure 4. The structure of Scientific Program Financing

2 The method applied in the research conducted was the personal interview method: Heads of 100 universities and 50 industrial companies collaborating within the framework of different national research programs were individually interviewed. 


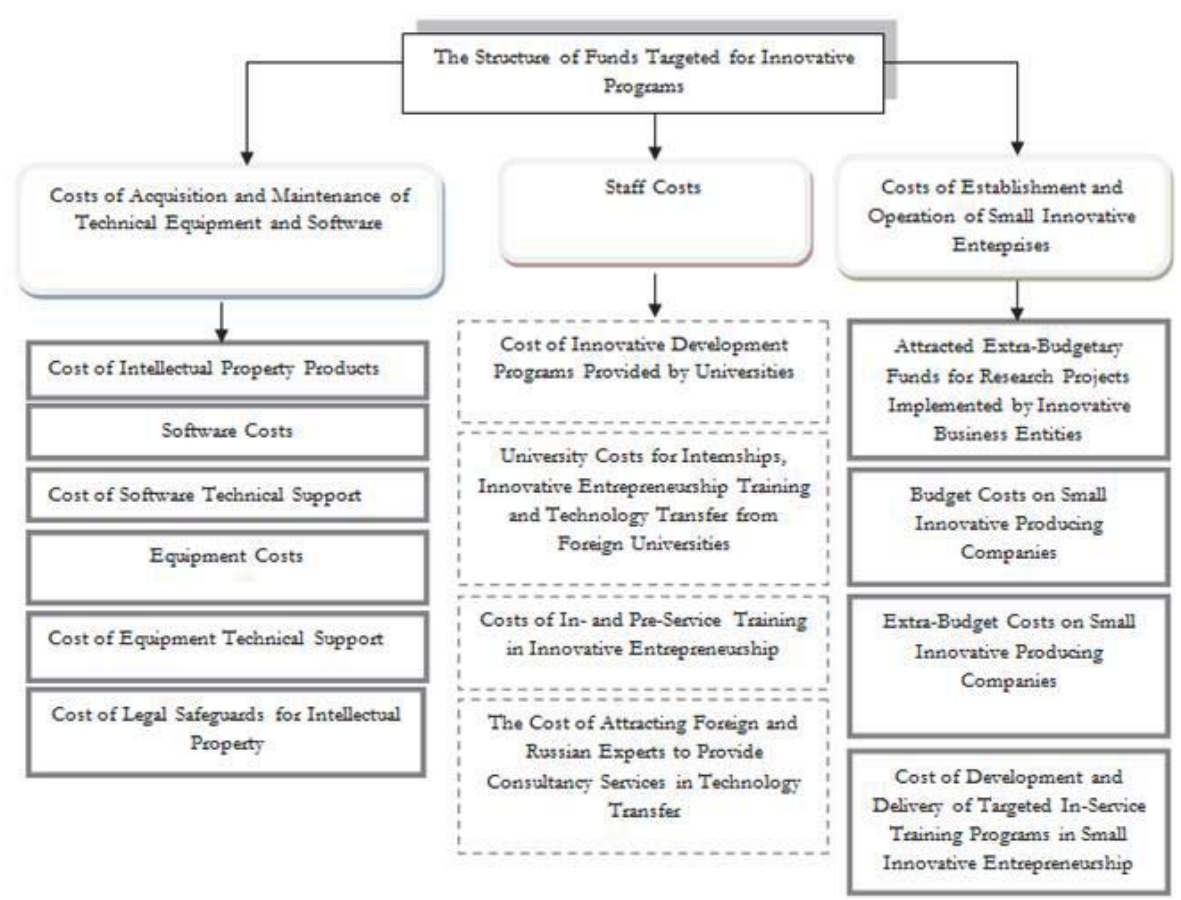

Figure 5. The Structure of Funds Targeted for Innovative Programs

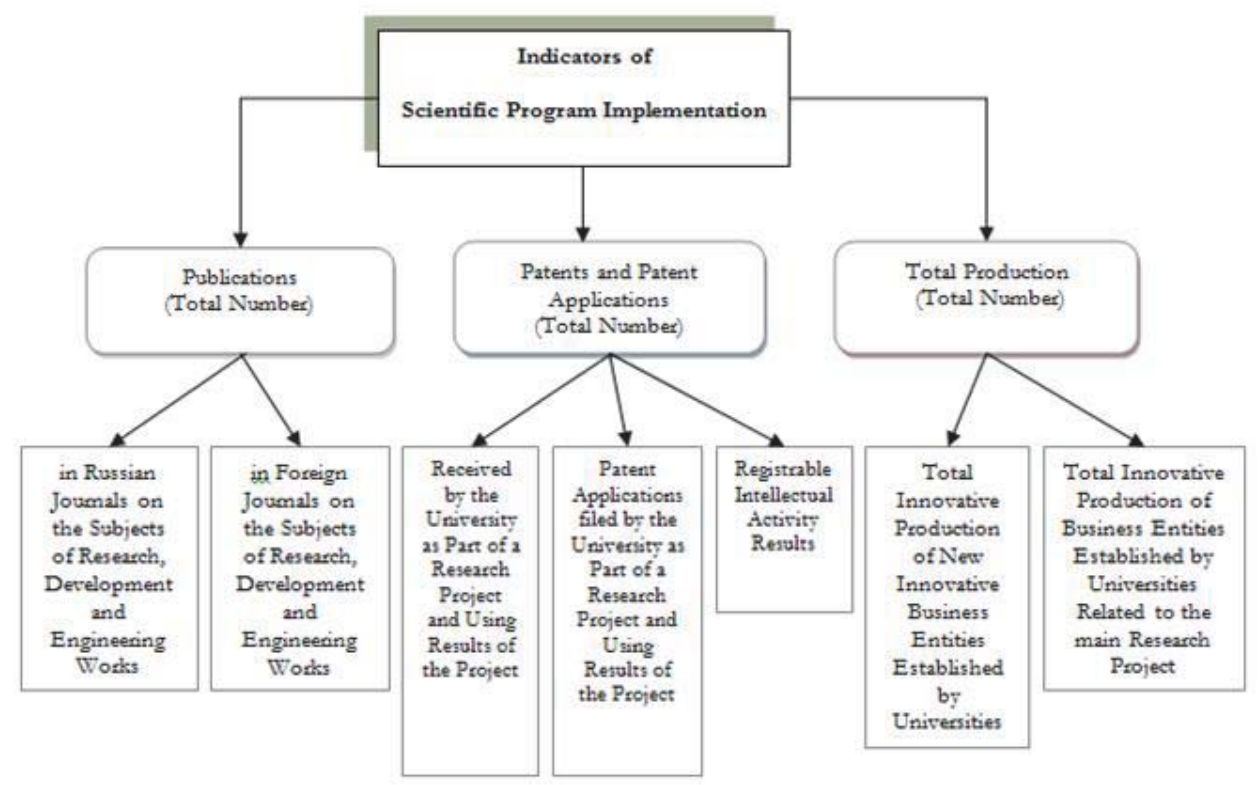

Figure 6. Indicators of Scientific Program Implementation 


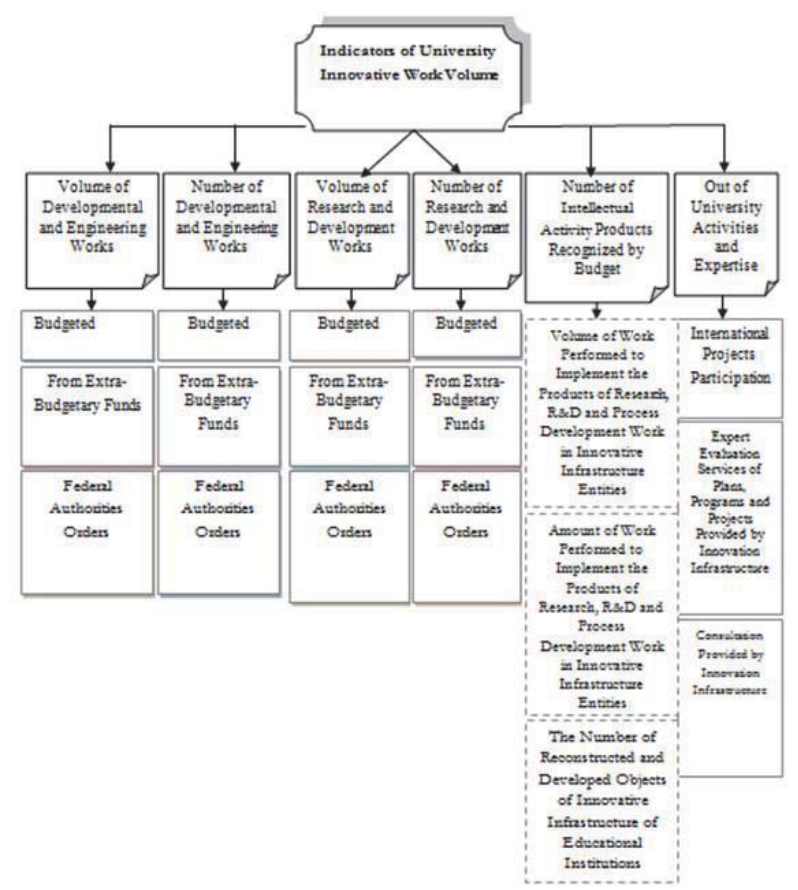

Figure 7. Indicators of University Innovative Work Volumes

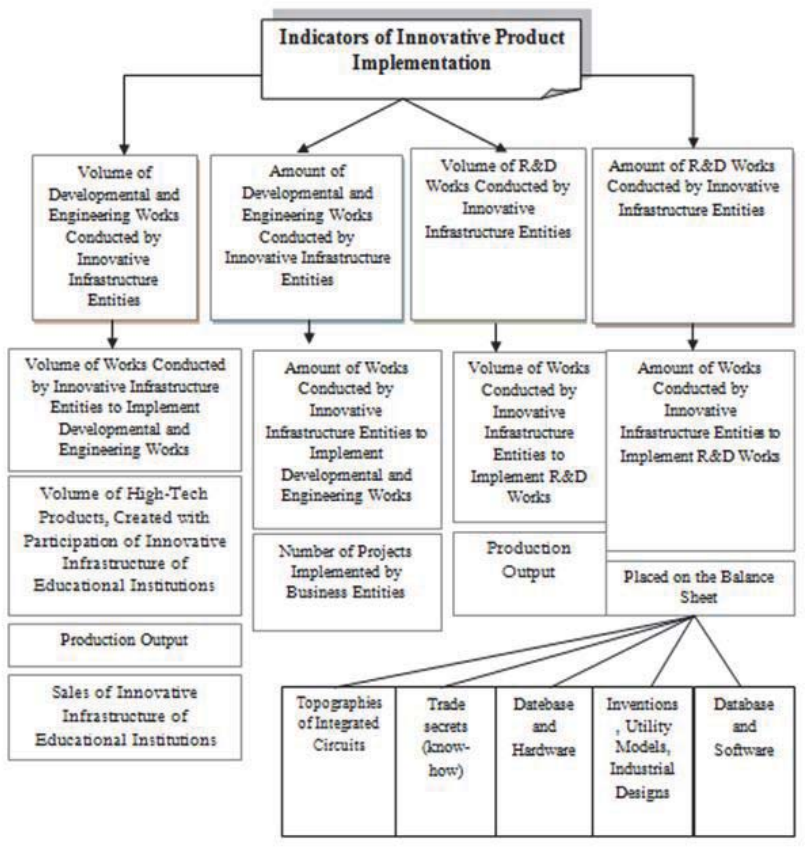

Figure 8. Indicators of Innovative Products Sales 


\section{Conclusions and Discussions}

Expert estimates suggest the following conclusions:

- Favorable expert evaluation was given only to the 'potential possibilities' of universities, they are not tested by the market, i.e., these are the experts' views only. The research did not discover any evidence of the views expressed, i.e. universities did not demonstrate capitalization of their research potentials;

- University's competitiveness and cooperation with other institutions and producers are nothing but "preconditions" as they are still pre-actions but not actions themselves;

- This situation is implicitly recognized by experts when their evaluation of a particular university's competitiveness in the international market of innovative products is extremely low;

- The economic efficiency of the research potential of a university drops to its minimum when experts point to the present (including up to year 2020) perspective inability of the University Research Departments to provide self-financing.

- The factorial analysis results of capitalization indicators evaluating the scientific potential of universities testify to the following:

- Humanitarian and economic universities tend to overestimate their ability to capitalize compared with its intellectual potential;

- Intellectual potential and the ability to capitalize of both, technical colleges and classical universities correspond to average estimates made by experts;

- For the potential of these types of universities, the experts find some miner differences: classical universities typically overestimate while technical colleges slightly underestimate their capitalization capabilities;

- Medical schools tend to underestimate their intellectual potential and ability to capitalize.

Research in all types of universities is unlikely to become self-sustaining. The experience gained by economically developed countries shows that if they are not supported by government contracts university science is unlikely to survive. The capitalization parameters of medical schools are especially low.

Research teams specializing in industries such as space technology and telecommunications, security and counter-terrorism, transport, aviation and space systems, aviation and space systems, energy efficiency and resource conservation, medical technology and pharmaceuticals, computer technology and software, information and telecommunication systems while competing with their Western colleagues demonstrate a profound lack of confidence.

The application of "virtual" favourable situation indices, implying that real implementation figures of some activities are accompanied with the parameters of those who intend to implement measures in the future, as well as the real situation analysis when "having intention" is not regarded as implementing measures, result in the following conclusions:

- Less than half of humanitarian, economic and medical schools participate in implementing government measures aimed at cooperation with partner companies;

- In classical universities the negative trend exemplifies the inability of universities to provide highly qualified staff to develop and teach development programs for their producing partners as universities are not manned for such activities;

- Technical, medical, and especially humanitarian and economic institutions of higher education demonstrate a lack or inefficiency of internship systems and in-house training programs for university academia and lifelong learning systems for their partners' staff.

University interaction with cooperative companies is aimed at facilitating the creation and implementation of scientific innovations, but existing mechanisms of this interaction in Russia suggest that universities and cooperative companies have just climbed their initial stage of partnership. This stage implies no more than just designing partnership governing documents and developing a management structure:

- $\quad 70 \%$ of the surveyed universities have established a system of pre- and in-house training for their partner company;

- $60 \%$ of the surveyed universities developed documents regulating the main areas of scientific cooperation with the partner company;

- $\quad 60 \%$ of the surveyed universities designed a mechanism (or principles) of innovations received by universities;

- $\quad 60 \%$ of the surveyed universities established administrative structures regulating scientific communication with partner companies;

- $60 \%$ of the surveyed universities have established a system of management of intellectual property (patents, 
licenses, know-how);

- $\quad 35 \%$ of the surveyed universities have introduced new mechanisms for the joint examination of scientific production.

- Factorial analysis of the indicators demonstrated the following:

- Classical universities are primarily focused on educational collaboration with partner companies, "supporting" some kind of organizational interaction; as for their attitude towards technological cooperation, it is typically negative;

- Technical, humanitarian and economic universities are more positive towards technological cooperation with partner companies; though avoid organizational types of cooperation. It is especially true about economic universities which seek to remain as "they are"; technical colleges are distinct from economic institutions and are not inclined to educational interaction with partner companies.

Experts believe that the implementation of joint innovation programs may imply a number of risks for cooperating parties. Among the most probable they name the following: market conditions for the period of innovative product commercialization are poor (specified by $80 \%$ of the experts), the innovative project period is too short ( $80 \%$ of the experts), the project cost of the innovation program is not enough $(80 \%$ of the experts), the commercialization of an innovative product is not guaranteed (75\% of the experts), innovation effect of the product is unjustified (50\% of the experts). There is lack of certainty in many aspects which indicates that a significant percentage of innovative research projects in the program are potentially risky. Basic risks in the priority areas are as follows:

- $\quad$ There are no criteria developed by universities to predict the commercialization of an innovative product;

- For areas like space technology and telecommunications, security and counter-terrorism, the risk factor lies in the lack of reliable evaluation of possible market variability for the period of an innovative product's commercialization.

Only half of the universities participate in implementing extensive joint programs with partner companies aimed at pre- and in-house training of professionals able to participate in innovative projects. The majority of higher educational institutions are only planning such activities for themselves.

What is considered urgent at the moment are students' internships and teachers' development programs conducted by and at partner companies: the situation is these areas is far from favourable. In a five-point assessment system with 'five' being the top grade, only three types of activities are to be assessed with 'a four'. They are as follows: university students' internships in partner companies, partner company participation in developing and upgrading university curricular and syllabi, developing the system of university graduate students' internships, coordination of pre- and in-house training programs with partner companies. There are three more types of activities which are very close to be evaluated as "four". They include: partner company employees involvement in teaching at universities, university graduate students' internships in partner companies and a favourable environment for partner companies staff lifelong learning.

Today, the situation is far from being favourable:

- University students' internships in partner companies are organized quite well, although a quarter of higher educational institutions do not practice students' internships in partner companies;

- Partner company participation in the updating of university curricular and syllabi as well as company employee involvement in university teaching is quite satisfactory, but approximately $40 \%$ of higher educational institutions do not practice any of the above mentioned;

- Coordination of staff development programs with higher educational institutions takes place in $55 \%$ of the surveyed institutions;

- Academia in half of the surveyed institutions are supposed to take development programs at partner companies.

There are quite typical complaints about the majority of large Russian firms, particularly in the oil industry, buying equipment and technology abroad, thus "investing in foreign industry" and depriving domestic developers and manufacturers of adequate development prospects. However, while assessing the existing situation the authors of the presented article find that the particular commercial interests of producing firms are to be considered crucial. Producing firms do invest in promising inventions only if they fit into the strategy of competition, but they do not usually have time, especially in transforming the economy of Russia, for long experimental testing (sometimes up to several years) of Russian know-how. While selecting the optimum form of innovative practices the emphasis should not be placed on the innovation itself, but on its ultimate goal. Who pays the piper, calls the tune, and in the market it is the consumer. One of the most important tasks is to foresee changes in consumer demands. The reliability "indicators" of such predictions are 
producers' marketing services. Only they determine preferable directions of research, profitability and its funding efficiency. Today, funding research for its own sake, in isolation from the final stage of the production process, must be considered a dead-end process. It is especially obvious due to the experience of foreign innovation incubators, which after successful implementation of the first stage of creative and experimental work faced difficulties implementing the commercial phase of the project, i.e. introduction of their innovative products into the market.

The authors also consider that the Russian policy maker's methods of universities interaction with enterprises should utilize the experience gained by developed countries that use a wide range of state mechanisms to support universities. On the one hand, it is the budget support of universities in the form of estimated financing costs, allocation of grants and placement of state orders for R\&D, investments in venture capital funds, as well as the implementation of targeted public procurement of innovative products and services; financing of business incubators, technology parks, etc. On the other hand, universities conducting research and development are provided with a variety of tax incentives; with institutions involved in innovative activities receiving government loans and loan guarantees.

\section{Acknowledgement}

This article was prepared on the basis of the results of scientific analysis carried out in agreement with the Ministry of Education and Science of the Russian Federation № 03.573.21.0006 for a grant from November 27, 2014 (code "201403-573-0046-001").

\section{References}

Dezhina, I.G. (2006). Evolution of Personnel Policy in the sphere of science. Society and Economy. 9. 173-187. (In Russian).

Dezhina, I.G. (2011). The Development of Science in Russian Universities as a New Priority of the State. Sociology of Science and Technology. Vol 2. 2. 38-47. (In Russian).

Klyucharev, G.A. (2015). On the Progress of Russian Education Reforms. Russia is reformed. Yearbook. Issue 13. Moscow: The Institute of Sociology. 324-346. (In Russian).

Krivosheeva, T.M., Kharitonov, T.V., Konovalov, E.E. (2009). Educating International Business Managers during the Integration of Russian Universities into the International Educational Environment. Moscow: Russian State University of Tourism and Service. (in Russian)

Kugel, S.A. (2014). The Adaptation Strategy of The Academic Research Community In Russia. Social Problems of the Innovative Development of Society. Collection of Scientific Papers. St. Petersburg: Nestor History. (In Russian).

Laursen, K. and Salter A. (2004) Searching high and low: what types of firms use universities as a source of innovation? Research Policy, Vol. 33. 1201-1215.

McGettigan, T. (2015). US: The Business of Higher Education. University World News. 31.05 .09 [Online] Available:http://www. universityworldnews.com/article.php?story=20090528172951762\&mode=print (May, 30, 2015).

Mikhaleva, M.N.(2014).Assessing the Level of Researchers and Optimizing the Structure of Higher Education in Russia. Sociology of Education. 12. 52-66. (In Russian).

National Science Board (2004). Science and Engineering Indicators - 2004. Arlington: National Science Foundation. Vol. 2. Appendix Tables. A3-31.

National Science Board (2010). Science and Engineering Indicators - 2010. Arlington: National Science Foundation. Appendix Table 310.

Osipov, G.V., Savinkov, V.I. (2014). Dynamics of PhD courses and the Perspectives up to 2030: Statistical and Sociological Analysis). Moscow: Institute of Socio-Political Research. (In Russian)

Osipov, G.V., Strikhanov, M.N., Sheregi, F.E. (2015). Competence-oriented Education of Engineers-Innovators. Sociology of Education. 4. $4-28$

Rakitov, A.I. (2003). Science and Science Studies of the XXI Century. Herald of Russian Academy of Sciences. Vol. 73. 2. 71-79.

Sheregi F.E., Klyucharev G.A. (2013). Partnerships between Companies, Universities and Research Institutions for the Implementation of Research Programs and Innovative Production. Toolkit for sociological faculties. Issue 4. Moscow: Centre for Social Forecasting and marketing. (In Russian).

Sheregi F.E., Riediger, A.V., Popov, M.S. (2014). Small Innovative Enterprises in Universities (Parts 1-3). Sociology of Education. 1. 2. 3.

Sheregi, F.E., Konstantinovsky, D.L., Arefiev A.L., (2006). Interaction of Russian Universities with International Foundations and Organizations. Moscow: Centre for Social Forecasting and marketing. (In Russian).

Sheregi, F.E., Strikhanov, M.N. (2012) Prospects of Cooperation between Industry and Science. Issue 2: Mechanisms for Partnership between Manufacturing Companies, Universities and Research Institutes. Moscow: Centre for Social Forecasting and marketing. (In Russian).

Sheregi, F.E. Strikhanov, M.N., Klyucharyov, G.A. (2012). Prospects of Cooperation between Industry and Science. Issue 5: Performance Criteria of Partnership between Manufacturing Companies, Universities and Research Institutes). Moscow: Centre 
for Social Forecasting and marketing. (In Russian).

Sheregi, F.E., Strikhanov, M.N., Savinkov, V.I. (2012). Prospects of Cooperation between Industry and Science. Issue I: Performance Criteria of Partnership between Manufacturing Companies, Universities and Research Institutes). Moscow: Centre for Social Forecasting and marketing. (In Russian).

Veryovkin, L.P., Hyles, G.V., Berdyklycheva, N.M. (2003). Experience of Organizing Innovation Activities Abroad. Education and Science in the Process of Reforms. Moscow: Centre for Social Forecasting. (In Russian).

Website of the International Association of Science Parks (2015). IASP - International Association of Science Parks [Online]. Available: http://www.iaspworld.org/ (May 30, 2015).

Zhurko, V.I., Divnenko, O.V. (2014). Mechanisms for Public-Private Partnerships and Professional Public Expertise in Higher Education. Moscow: IMSGS. (In Russian). 